\title{
Meperidine to control shivering associated with platelet transfusion reaction
}

Shivering may be part of a febrile non-haemolytic reaction to blood product transfusion. Shivering can increase oxygen consumption up to 500 per cent which may be detrimental to patients with decreased myocardial reserve. A case is presented of a reaction to platelet transfusion characterized by shivering, tachycardia and hypertension in a patient with a recent myocardial infarction in whom the metabolic and haemodynamic effects were considered to be potentially disastrous. Intravenous injection of meperidine was rapidly effective in treating these changes.

Shivering is often seen following general and regional anaesthesia. ${ }^{1,2}$ Shivering is also observed following administration of drugs such as amphotericin $B$ and in the course of a reaction to blood products. ${ }^{3,4}$ Although the aetiology and clinical presentation may vary, shivering may have harmful effects. Shivering can interfere with monitoring, can disrupt surgical wounds and dressings, but can have its most serious effect on patients with decreased cardiac and pulmonary reserves. ${ }^{5}$ This is because shivering can increase oxygen consumption up to 500 per cent, thereby increasing myocardial work and contributing to hypoxaemia. ${ }^{6.7}$ Hypoxaemia associated with postoperative shivering has been implicated as a cause of myocardial infarction. ${ }^{7}$ A case of severe shivering, apparently part of a febrile non-haemolytic transfusion reaction to platelets is presented.

\section{Key words}

TRANSFUSION: reaction, platelet; COMPLICATIONS: myocardial infarction, shivering.

From the Department of Anaesthesia, Intensive Care Unit, St. Michael's Hospital, University of Toronto, Toronto, Ontario.

Address correspondence to: Dr. W.H. Noble, Department of Anaesthesia, St. Michael's Hospital, 30 Bond Street, Toronto, Ontario, M5B IW8.

\section{Case report}

A 43-year-old male with unstable angina underwent percutaneous transluminal coronary angioplasty. The procedure was complicated by ventricular tachycardia and acute pulmonary oedema. An intra-aortic balloon pump (IABP) was inserted through the femoral artery and the patient was transferred to the operating room where he underwent uneventful two vessel aorto-coronary bypass grafting. The patient was transferred to the Intensive Care Unit haemodynamically stable, lungs mechanically ventilated, IABP in situ and on minimal inotropic support.

Electrocardiogram and cardiac enzyme studies confirmed a new anteroseptal myocardial infarction but the patient made a good recovery over the next 24 hours. Inotropes were rapidly discontinued, he was successfully weaned from the ventilator and his trachea extubated. The surgeon removed the balloon pump but after 30 minutes the patient still required femoral artery pressure because of continued bleeding. Prothrombin and partial thromboplastin time and platelet count were normal. The patient had been receiving aspirin before surgery and a presumptive diagnosis of ASA-induced platelet dysfunction was made. Four units of platelets were transfused. The bleeding had stopped by the time the transfusion was started but at its completion the patient began to shiver vigorously. Heart rate increased from 84 to 180 beats per minute and blood pressure from $130 / 50$ to $160 / 55 \mathrm{mmHg}$. The patient became very anxious and agitated. An infusion of normal saline using new IV tubing was started and $50 \mathrm{mg}$ diphenhydramine was administered IV. No change was noted after three minutes. Propranolol $0.5 \mathrm{mg}$ was given twice IV with a slowing in the heart rate to about 150 beats per minute, but vigorous shivering continued. Meperidine $50 \mathrm{mg}$ was given IV. Within one minute the shivering had stopped completely. Within two minutes the heart rate and blood pressure returned to pre-reaction levels. The patient was drowsy for about five minutes but was thereafter alert and comfortable. Temperature remained unchanged at $38.9^{\circ} \mathrm{C}$ and there was no evidence of urticarial rash. The patient had no chest pain or further ECG changes. Temperature increased to $40^{\circ} \mathrm{C}$ two hours later but decreased in response to oral acetamin- 
ophen. Subsequent blood cultures were negative for bacterial growth.

\section{Discussion}

Platelet concentrate transfusion may be complicated by immune mediated reactions such as febrile nonhaemolytic (FNH) reactions or post-transfusion purpura and non-immune mediated reactions such as bacterial contamination. ABO incompatible platelet preparations are frequently used and may have been transfused in the patient described. Such platelets achieve similar haemostasis to compatible concentrates but platelet destruction may occur. $A B O$ incompatible reactions due to red cells are possible hence $\mathrm{ABO}$ compatible preparations are preferred. $^{8}$

All platelet preparations contain some white cells and red cells. Most FNH reactions are considered to be due to HLA antigens which are found mainly on white cells but also in minute quantities on platelets. FNH reactions are usually delayed about 30 minutes after contact and are characterised to a varying degree, by fever, tachycardia, shaking chills and acute patient discomfort. Most reactions are self-limiting and usually antipyretics are sufficient treatment. ${ }^{4.9 .10}$

The shivering reaction, as described in this patient, places increased demands on myocardial and respiratory function. By increasing oxygen demand, oxygen transport must be increased to meet that demand. ${ }^{11}$ When coronary or myocardial dysfunction places a limit on the appropriate response, then tissue hypoxia must follow. The effect of tachycardia and hypertension on the compromised heart will further predispose to myocardial ischaemia and possibly infarction.

Meperidine has been used to treat shivering following regional and general anaesthesia. ${ }^{12,13}$ Fentanyl and morphine are not as effective in treating postoperative shivering. ${ }^{14}$ Several reports have also been made of the use of meperidine to treat the shaking chills following amphotericin B and granulocyte transfusion. ${ }^{3.15}$ Though this treatment is known to haematologists, as far as the authors are aware it is not in common use to treat shivering following blood and platelet transfusion reactions. ${ }^{4}$ The advantages of meperidine include rapid and effective results, sedation and analgesia and the avoidance of long-acting muscle relaxants or the acute hypotensive effect of chlorpromazine. Disadvantages of meperidine include nausea and vomiting, respiratory and myocardial depression when used in larger doses. Nausea may be easy to treat but the risk:benefit ratio of respiratory and myocardial depression versus the effects of increased oxygen demand of shivering (and in this patient tachycardia and hypertension) must be carefully considered.
In this patient with a history of recent myocardial infarction, meperidine was rapidly effective in treating the effects of a platelet transfusion reaction with its potentially lethal complications of shivering, hypertension and tachycardia.

\section{Acknowledgements}

The authors wish to thank Dr. J.J. Freedman for his expert advice and Ms. Kerry McClenaghan for preparation of the manuscript.

\section{References}

1 Moir DD, Doyle PM. Halothane and postoperative shivering. Anesth Analg 1963; 42: 423-8.

2 Brownridge $P$. Shivering related to epidural blockade with bupivacaine in labour, and the influence of epidural pethidine. Anaesth Intensive Care 1986; 14: 412-7.

3 Burks LC, Aisner J, Fortner CL, Wiernik PH. Meperidine for the treatment of shaking chills and fever. Arch Intern Med 1980; 140: 383-4.

4 Widman FK (Ed.). Technical Manual, American Association of Blood Banks. 9th ed. 1985: 333.

5 Dawkins JM. Halothane. Lancet 1961; 2: 1259.

6 Bay $J, N$ Nn $J F$, Prys-Roberts $C$. Factors influencing arterial $\mathrm{PO}_{2}$ during recovery from anaesthesia. $\mathrm{Br} \mathrm{J}$ Anaesth 1968; 40: 398-407.

7 Gonzales ER. Stopping post-op shivers eases rewarming. JAMA 1982; 248: 2802 .

8 Miller RD. Anesthesia. 2nd ed., New York: Churchill Livingstone Inc., 1986: 1358.

9 Herst $R$ (Ed.). Clinical Guide to Transfusion. Canadian Red Cross Society Blood Services. 1987: 8-9.

10 Mollison $P L$, Engelfriet $C P$, Contreras $M$. Blood Transfusion in Clinical Medicine. 8th ed. Oxford: Blackwell Scientific Publications, 725-6.

11 Horvath SM, Spurr GB, Hut BK, Hamilion LH. The metabolic cost of shivering. J Appl Physiol 1956; 8 : 595-602.

12 Casey WF, Smith CE, Karz JM, O'Loughlin K, Weeks SK. Intravenous meperidine for control of shivering during Caesarean section under epidural anaesthesia. Can J Anaesth 1988; 35: 128-33.

13 Cohen $M$. An investigation into shivering following anaesthesia: preliminary report. Proc Roy Soc Med 1967; 60: 18-9.

14 Pauca AL, Savage RT, Simpson S. Effect of pethidine, fentanyl and morphine on post-operative shivering in man. Acta Anaesthesiol Scand 1984; $28: 138-43$.

15 Djeressi l, Jung Sun Kim. The Granulocyte: Function and Utilization. Alan R. Liss Inc. 1977, p. 312, New York 
Résumé

Le frisson peut être le signe d' une réaction non-hémolytique à la transfusion de dérivés sanguins. Il peut augmenter la consommation d'oxygène par un facteur de cinq, exercice coûteux pour un coeur aux réserves limitées. Peu après un infarctus du myocarde, un de nos patients a reçu une transfusion de concentrés plaquettaires et il développa rapidement des tremblements avec tachycardie et hypertension dont les conséquences méraboliques et hémodynamiques nous faisaiem craindre le pire. Pour traiter cette complication, l'injection intraveinause de mépéridine s'avéra rapidement efficace. 